US report looks abroad for ideas

\section{Washington}

The Energy Research Advisory Board (ERAB) of the US government has issued its preliminary advice on a critical study of the fate of the Department of Energy's (DoE) national laboratories. This is a key study because the laboratories are also being looked at by the White House, which may not be favourably inclined towards them and will have much to say about their future.

At stake is the role of nine facilities (see below), some of which do the most intensive high technology research in the world - on atomic weapons, fusion and lasers - gobbling up $\$ 2,300$ million, or half of DoE's annual research and development budget each year. Apart from their atomic weapons work, they are entirely the creatures of DoE. Starkly put, the choice is whether the laboratories should throw their doors open to become national centres, performing research for other federal departments, private industry, perhaps even other countries, or whether, as budgets decline, they should concentrate on a few things they do well and consolidate, with some of them closing down.

The debate will be joined in the autumn when the ERAB panel makes a final report. At that time, the White House Science Advisory Committee will be studying the fate of the DoE laboratories and those of the Department of Defense. Mr George A. Keyworth II, the President's science adviser and an alumnus of Los Alamos, has said that he thinks some of the laboratories should close down. Last December, the Administration proposed that all DoE research be moved to the Department of Commerce, a suggestion that no one in Washington now takes seriously. And James Edwards, Secretary of DoE, surprised ERAB recently when he told them that, in his view, the laboratories should remain in existence and throw their doors open to become national technical centres. So the discussion, once joined, will be lively.

The ERAB panel is headed by Ivan Bennett, dean and provost of New York University Medical Center. DoE requested the study last September. A preliminary report was sought this spring to feed into the White House's review. Although the group has not decided its own view of the laboratories' fate, the preliminary report outlines the laboratories' strengths and future options.

Some of the institutions, like Los
Alamos, were founded as part of the weapons programme and retain important roles in weapons research. Others, such as Ames Research Laboratory run by the University of Iowa for DoE, do basic research. Oak Ridge has undergone a major transformation into a general applied research laboratory since its beginnings during the Manhattan project.

The appendix to the ERAB panel's report deals with how major laboratories in other countries have adapted to changing times or to the stark fact of having fulfilled their mission. The UK Atomic Energy

\section{National laboratories covered in the ERAB report}

Ames Laboratory

Argonne National Laboratory

Brookhaven National Laboratory

Los Alamos National Laboratory

Lawrence Berkeley Laboratory

Lawrence Livermore National Laboratory

Oak Ridge National Laboratory

Pacific Northwest Laboratory

Sandia Laboratories

Authority's laboratories at Harwell are discussed at some length. Founded in 1946 to assist in developing civilian nuclear power, Harwell's task was nearly complete by the mid-1960s. Then, the report notes, Harwell kept the same disciplines but took on new clients outside the government's agency. The lesson of Harwell, it states, is that "once a large laboratory has been assembled, it can be useful to government in fields that extend far beyond its original

mission and that such organizations can indeed change their mission without loss of vitality."

Other examples from abroad are Amersham International, the UK government's source of radioisotopes which has been spun off as a company, and France, where government laboratories commonly create companies to perform specific work for industry. The report notes the Dutch pattern of numerous small laboratories, which are two-thirds government-sponsored and one-third sponsored by industry.

Sweden's Studsvik Energiteknik AB, the government's energy laboratory, had three years' warning that its government funding would be cut by 70 per cent. The three years enabled the group to make a smooth transition to becoming predominantly sponsored by outside interests.

The implication for the US national laboratories is that they can adapt and so probably should.

The carefully worded list of options presented by ERAB includes: "concentrating" the laboratories' efforts through vigorous management by the DoE; freeing them of legal constraints so they can work for other sponsors; transferring other federal tasks to them, making them more multi-faceted or narrowing their mission "to correspond with resources allotted"; closing one or more laboratories, or mergers. The suggestions are intriguing, but to implement any one of them will be a gargantuan task.

Deborah Shapley

\title{
Disarray on chemicals control
}

\section{Brussels}

Fears are growing in environmental circles that the special programme on the control of potentially hazardous chemicals set up by the Paris-based Organization for Economic Cooperation and Development (OECD), is running into difficulties as a result of the Reagan Administration's proindustry and protectionist policies. The downgrading of the US Environmental Protection Agency (EPA) has coincided with a loose implementation of the toxic substances control act (TOSCA). Jacqueline Warren of the Natural Resources Defence Council, a leading environmental pressure group, has cited EPA figures on the premarketing notifications for new chemicals submitted since April 1979 showing that 66 per cent of submitted notices failed to include toxicity data, thus undermining progress to establish procedures to reduce the risk of new chemicals.

Officials at OECD's headquarters are cagey, in view of the United States' negotiating weight, about admitting allegations that the enthusiasm evident under the Carter Administration for the OECD programme has waned. A legislative gulf has certainly grown between the United States and the EEC, as a result of the way that TOSCA is being implemented and the changes within the EEC after the Sixth Amendment came into force last September. This is likely to impair prospects for rapid agreement within OECD.

Under the Sixth Amendment of the 1967 directive on dangerous substances companies must submit a stringent premarketing dossier on a new substance not only to national authorities but also to the European Commission and to the other member states. Not surprisingly, EEC countries are now disappointed that disagreements within the OECD still loom large in two crucial areas which appear to have been resolved by the 6th Amendment. In October this year a high level OECD meeting will be tackling the areas in 